\title{
THE DEPARTMENT OF SURVEY AND EXCAVATION METHODOLOGY OF THE GERMAN ARCHAEOLOGICAL INSTITUTE IN FRANKFURT
}

\author{
Knut Rassmann - Isabel Hohle - Roman Scholz - Hajo Höhler-Brockmann - Johannes Kalmbach - \\ Jessica Schmauderer - Maria Kohle - Melani Podgorelec - Eszter Bánffy \\ Hungarian Archaeology vol. 9 (2020), Issue 1, pp. 51-55, https://doi.org/10.36338/ha.2020.1.1
}

The Römisch-Germanische Kommission (RGK), the research institute of the German Archaeological Institute (DAI) in Frankfurt has initiated countless new research methods since its foundation almost 120 years ago. The Technical Department established in 2010 was mainly engaged in archaeophysical surveys conducted over large areas and geomagnetic prospection involving the documentation of the variations in an area's magnetic field, a routine practice by then. Since then, its activities have expanded to include various non-invasive or minimally invasive analytical procedures for the examination of archaeological finds. Owing to experimentation with, and testing of, various new methods, our team has grown into a genuine competence centre during the past few years, an achievement that was fully recognized in 2019, when the department was renamed Department of Survey and Excavation Methodology (Referat für Prospektions- und Grabungsmethodik). There are few Referats in the German Archaeological Institute, one of these being the Department of Architecture (Architekturreferat) whose main concern in the architecture of built monuments and heritage protection. In addition to our own excavations, field projects and archaeometric analyses, our centre is also involved in the research projects of our partners and we assist, to the best of our abilities, our external colleagues. Given the many diverse research methods utilising the new equipment of the RGK, in the following we offer an overview of our activities and the employed methods and procedures (Fig. 1).

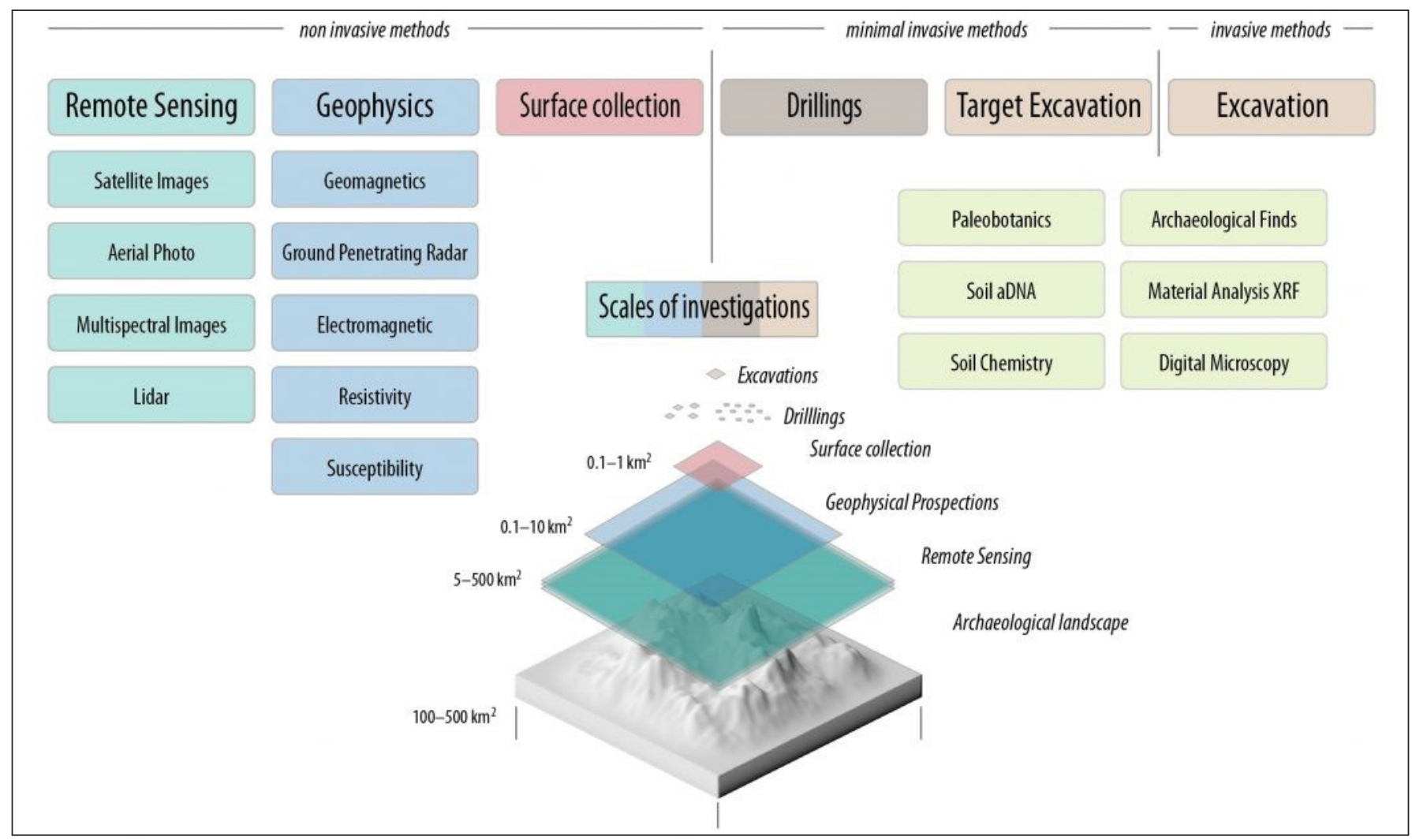

Fig. 1. Overview of the activity of the RGK's Department of Survey and Excavation Methodology

(K. Rassmann / H. Höhler-Brockmann) 
Knut Rassmann et al. $・$ The Department of Survey and Excavation Methodology of the German Archaeological Institute

\section{D MODELLING AND THE USE OF DRONES}

The first steps in any archaeological investigation, whether of a landscape, a site, a find assemblage or a particular artefact, involve the detailed documentation of the existing condition(s). We have been using image-based 3D modelling methods (often called SfM, Structure from Motion) for this purpose, in order to generate high-resolution, 3D images of an artefact, feature or terrain surface. This type of modelling is of

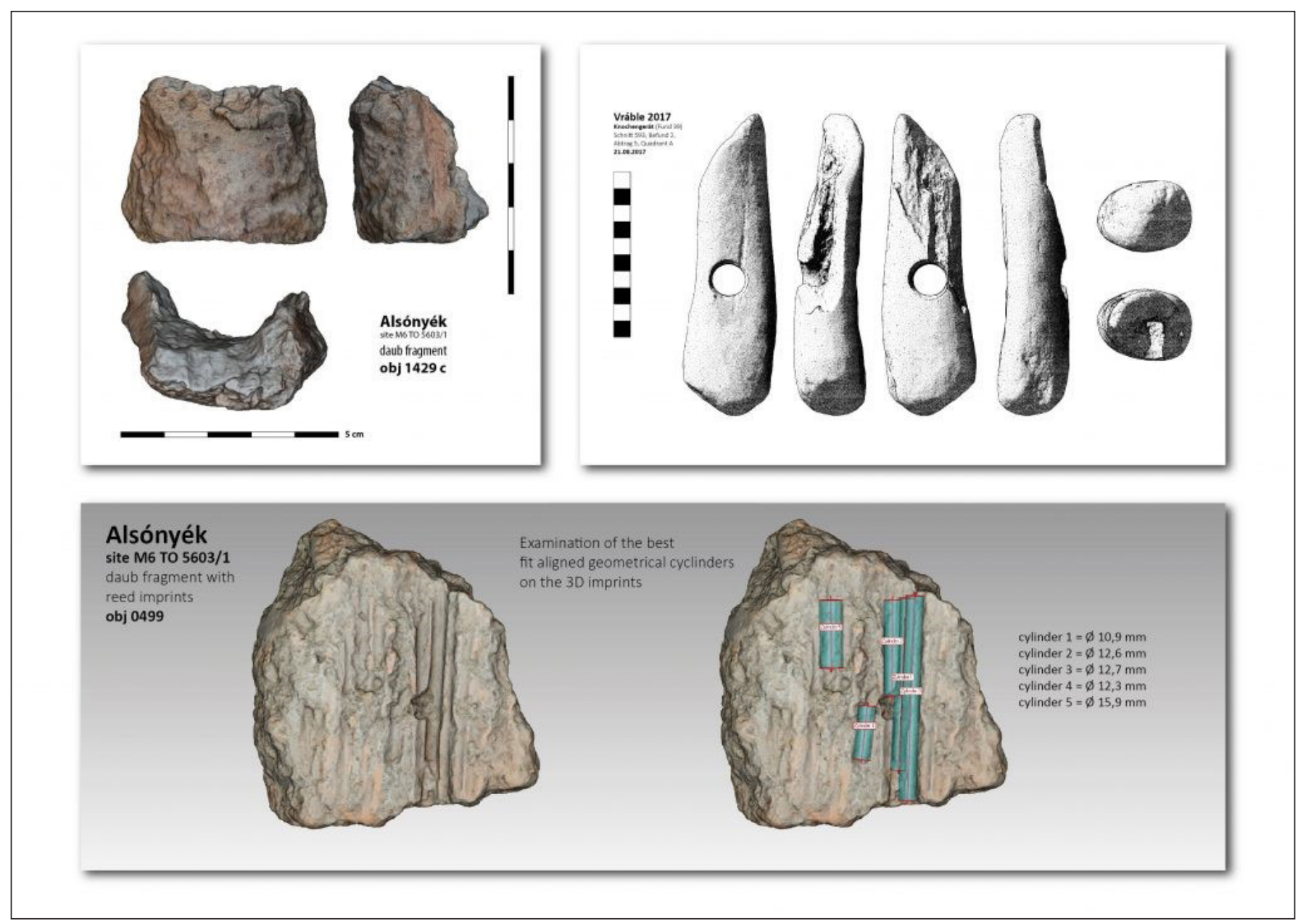

Fig. 2. A few examples of the 3D digital documentation of archaeological finds (H. Höhler-Brockmann)

immense aid in any assessment and interpretation, particularly in cases of complex situations involving a wide range of information, irrespective of whether we are analysing a burnt daub fragment or an extensive Copper Age settlement (Fig. 2). Our options are to some extent influenced by the available equipment and our research questions.

We have a wide array of equipment at our disposal for field documentation, including a portable light tent, lamps, tripods and turntables, all of which can be stored in a photo backpack. For landscape documentation, we use a so-called Unmanned Aerial Vehicle (UAV) system, better known as drones. There are many different types, ranging from simple small drones that can be carried in a handbag, which

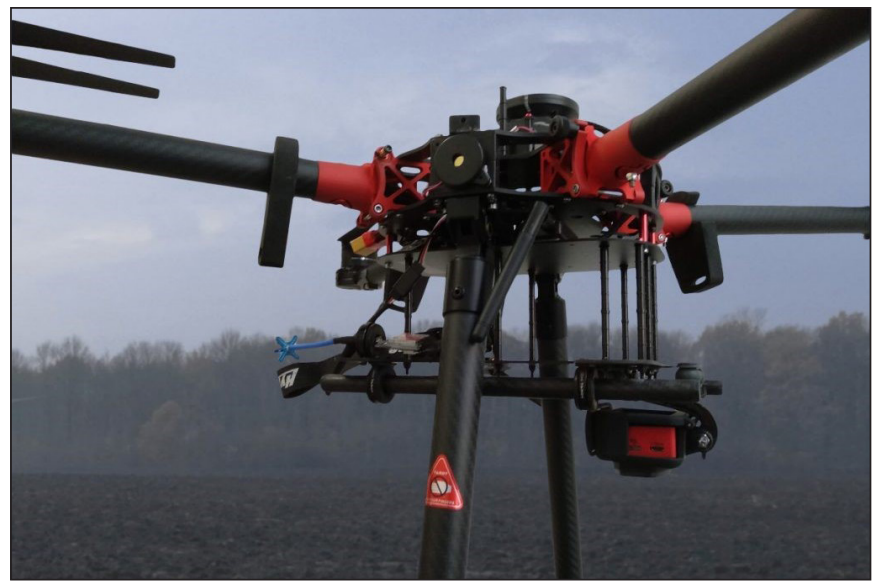

Fig. 3. Pre-flight preparation of a drone at ÖcsödKováshalom in the Tisza region. The fully pre-programmable drone was equipped with a multispectral sensor (H. Höhler-Brockmann) 
Knut Rassmann et al. $・$ The Department of Survey and Excavation Methodology of the German Archaeological Institute

are suitable for a quick survey, to types that can be pre-programmed and are equipped with a full-frame camera and other instruments such as a multispectral sensor suitable for taking a series of other measurements (Fig. 3).

\section{GEOMAGNETIC PROSPECTION}

We have undertaken the non-invasive magnetic prospection of archaeological landscapes since 2003. Since then, we have continuously improved prospecting techniques and the necessary technical know-how during our fieldwork, and thus the data collected in the field can be interpreted using various programs and filters. Obviously, the data obtained using these techniques need to be of the highest possible quality to ensure, among others, that they will be suitable for future assessments undertaken with novel techniques that will open hitherto unknown avenues of interpretation. Experimentation, testing, familiarising ourselves with new techniques and the integration of various research techniques benefits both our own research and our network of German and foreign colleagues.

For large-scale prospections, we use our vehicle-towed 14-channel magnetometer system. The choice of towing vehicle depends on the terrain and the soil structure (Fig. 4). We usually prefer to use a SUV or our recently purchased quad. The advantage of the 14-channel system is that owing to its $3.5 \mathrm{~m}$ width, it can be transported without the need for a trailer and that it is suitable for the geophysical survey of large areas, as much as 10 to 30 ha per day, depending on the terrain, the soil structure and the weather conditions.

The department also has a 5-channel magnetometer system that can be mounted on a push-cart or towed by a quad. This small instrument is ideal for surveying smaller areas such as field boundaries or areas that are more difficult to access (Fig. 5).

We created this system based on these two instruments, enabling us to open windows onto archaeologically important landscapes and to gain a better understanding of the immediate area of already known sites, after a longer period of testing and experimentation.

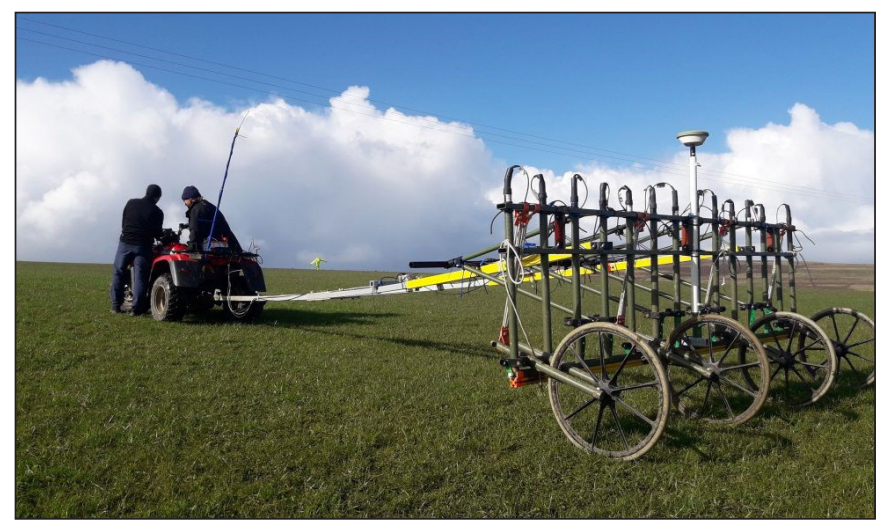

Fig. 4. Prospecting with the 5-channel magnetometer in the area of the tell settlement at Hódmezövásárhely-Gorzsa (R. Scholz)

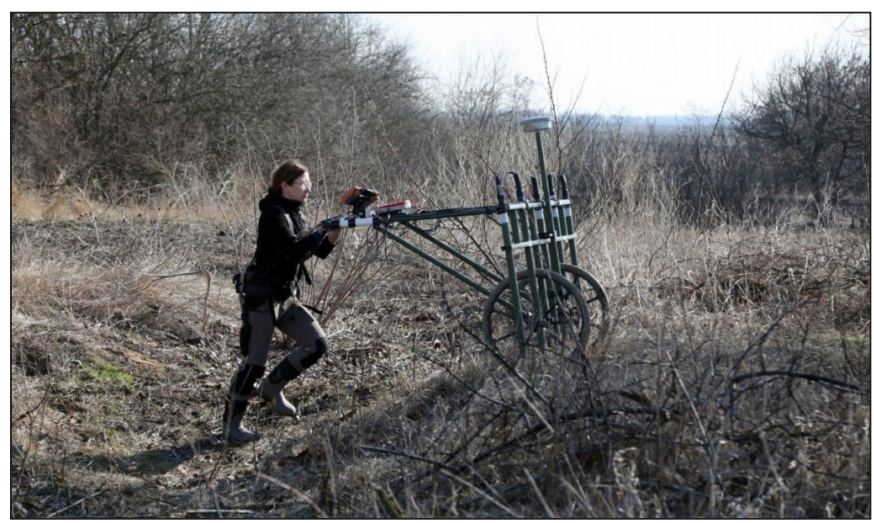

Fig. 5. Prospecting with the 14-channel system in the valley of the River Boyne in Ireland (J. Kalmbach)

\section{THE RGK LABORATORY: ANALYSIS OF THE FINDS AND OF SOIL SAMPLES THAT HAVE BECOME AN IMPORTANT SOURCE OF ARCHAEOLOGICAL INFORMATION}

In addition to non-invasive analytical techniques, we also conduct minimal invasive analyses. These include the examination of soil samples extracted by coring. The sampling locations are selected on the basis of the results of the preliminary geomagnetic prospection. These are usually archaeological features within a settlement, a house or a burial, which offer additional information on the structure and sequence of the layers, as well as on their diachronic changes. Layers in the soil cores are radiocarbon-dated, which is of aid in determining the start and end of the use of a particular archaeological feature (Fig. 6). Micro-remains such as pollen and inorganic vegetal phytoliths provide information on the one-time vegetation, while charred cereal grains and fruit seeds offer insights into a period's farming practices and diet. 
Knut Rassmann et al. - The Department of Survey and Excavation Methodology of the German Archaeological Institute

With the help of a special instrument, the susceptibility measuring instrument, we can measure the changes in the magnetic excitability of the sediments in the cores, which offer insights into the "history" of the superimposed layers. The phosphate values of the sediment samples offer information on settlement intensity, on the extent of human impacts: permanently occupied settlements with accumulations of decomposed organic matter, including human and animal waste, yield high phosphate values. We use a portable X-ray fluorescence spectroscope for collecting data from a particular area or feature during an excavation. During the past few years, we have examined over five thousand soil samples collected from archaeological sites and from off-site locations of important archaeological landscapes. One-half of each core is archived and preserved for the future for practical and ethical considerations (for the protection of the archaeological heritage) to ensure that they can be used for further sampling as new and more accurate analytical methods are developed. Simultaneously, we are exploring new, exciting fields: for example, we have begun the genetic analysis of soil bacteria in collaboration with the Max Planck Institute of Leipzig, a truly novel and experimental project!

In addition to the analyses and documentation of the soil samples gained by coring, there is yet another field to which the RGK laboratory devotes its research energies, namely the analysis of archaeological finds using our Keyence digital microscope, which enables an up to $2000 \times$ magnification, allows us, for example, to gain a better understanding of manufacturing techniques, providing invaluable information, for example, on the technical details of ceramic vessels such as the properties of the raw material and the tempering agents. We can also use it to examine use-wear traces on tools and to enlarge images of these traces. The 3D function enables the documentation and visualisation of the tiniest details on an artefact's surface. One of our current projects involves the examination of possible signs of post-mortem manipulations on human bones (Fig. 7). The archaeometric and taphonomic analyses on these archaeological finds, which also focus on what happened to them after they were discarded, can provide answers to a series of questions regarding manufacturing processes, whether they had been repaired or re-used, whether they had been

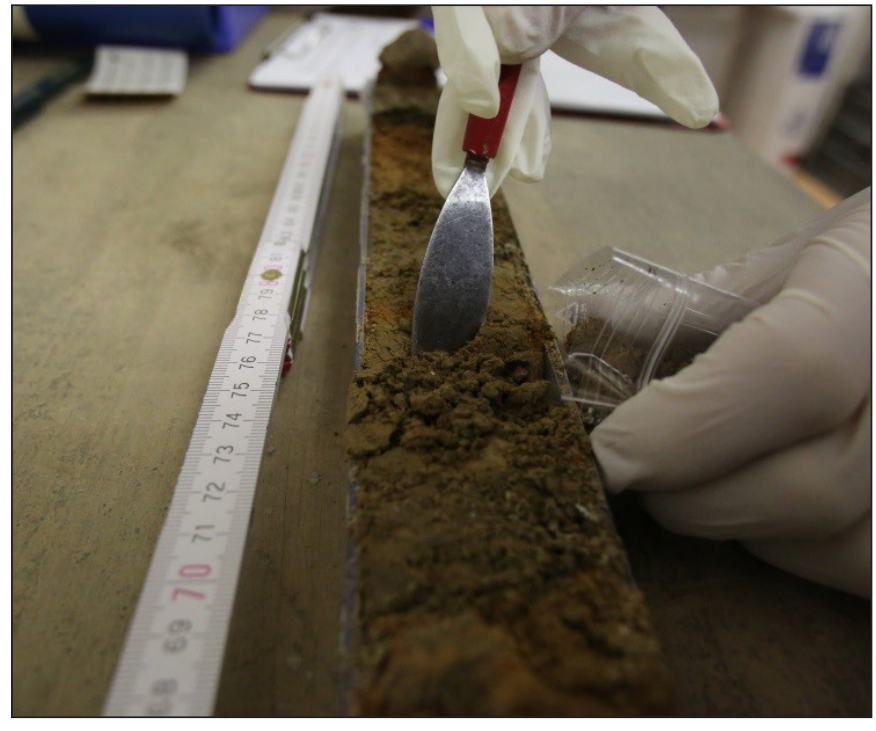

Fig. 6. Layer sequence of a soil core. The halved core is ready for documentation and for the sampling of certain layers (J. Kalmbach)

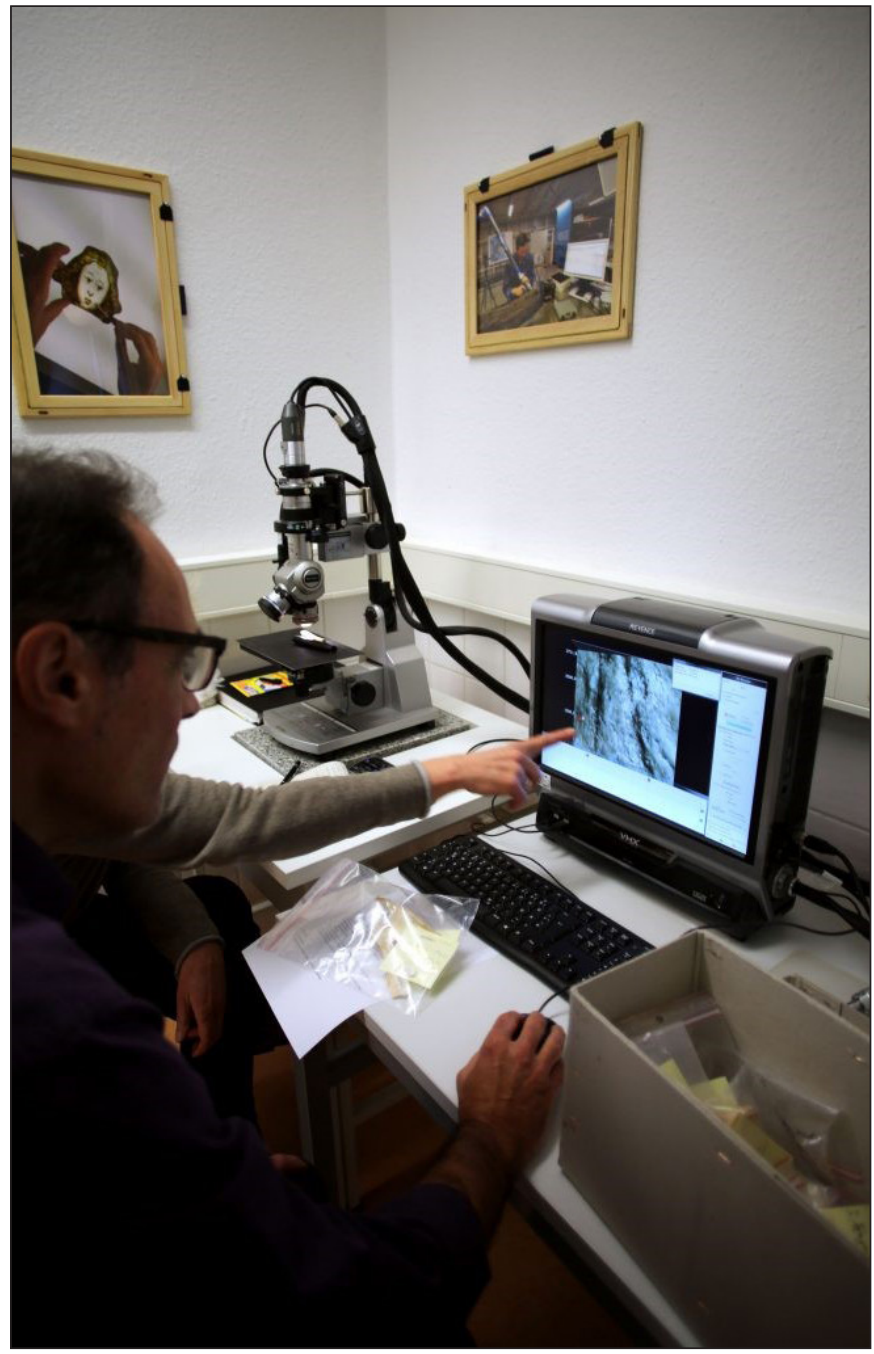

Fig. 7. A digital miscroscope during use: the examination of the structure of intentional cuts on the Neolithic skulls and long bones from Herxheim in south-western Germany (J. Kalmbach) 
Knut Rassmann et al. $・$ The Department of Survey and Excavation Methodology of the German Archaeological Institute

simply discarded or intentionally deposited. In this sense, the examination of various objects using digital microscopes contributes a wealth of new information to understanding past societies.

\section{UNDERWATER ARCHAEOLOGY}

In addition to the many methods described in the foregoing, we are also involved in underwater archaeology, even if our main interest is one of methodology. In collaboration with the UNESCO Centre for Underwater Archaeology in Zadar, Croatia (https:// icua.hr/en), we are working on developing new documentation methods, as well as improving already existing ones, specifically for underwater work. We succeeded in fully excavating a sixteenth-century wreck in the Adriatic and, using a modified version of the SfM method mentioned above, we were able to create a 3D model of the ship from thousands of 3D photos. Even more importantly, we could also develop and test various methods for the protection and preservation of similar wrecks. Currently, we are partaking in the preservation and conserva-

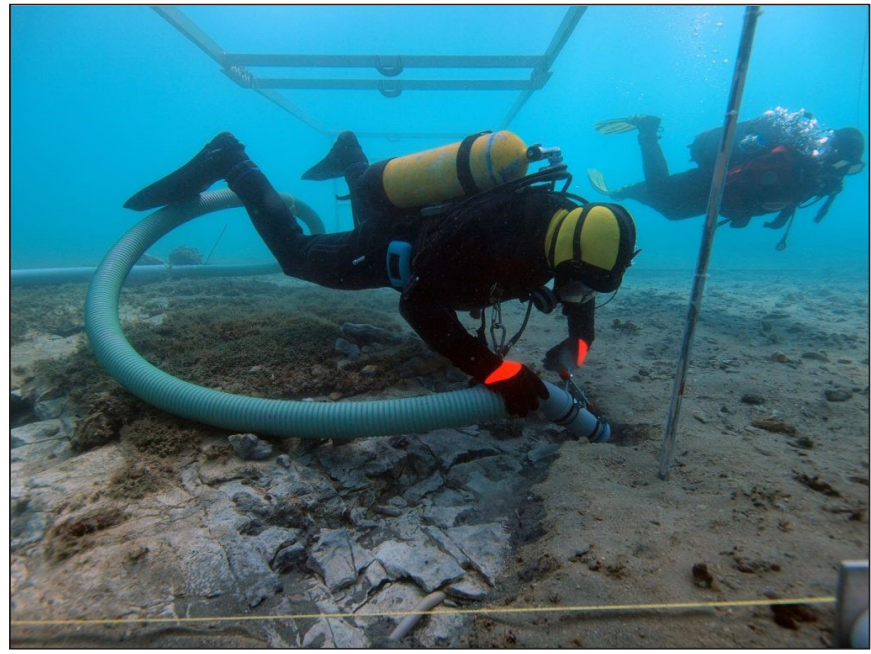

Fig. 8. Excavation of the Pula wreck and its finds in 2016 (M. Pešić, ICUA Zadar) tion of a wreck off the Croatian city of Pula, in the course of which we employ some of these methods (Figs 8-9). The investigation of a nearby late antique villa and its (currently underwater) harbour is conducted as part of a new Croatian-German project.

Information on the new research projects and publications as well as other news of interest of the Römisch-Germanische Kommission (RGK), the research institute of the German Archaeological Institute (DAI) in Frankfurt can be found on our regularly updated blog and on our Facebook page.

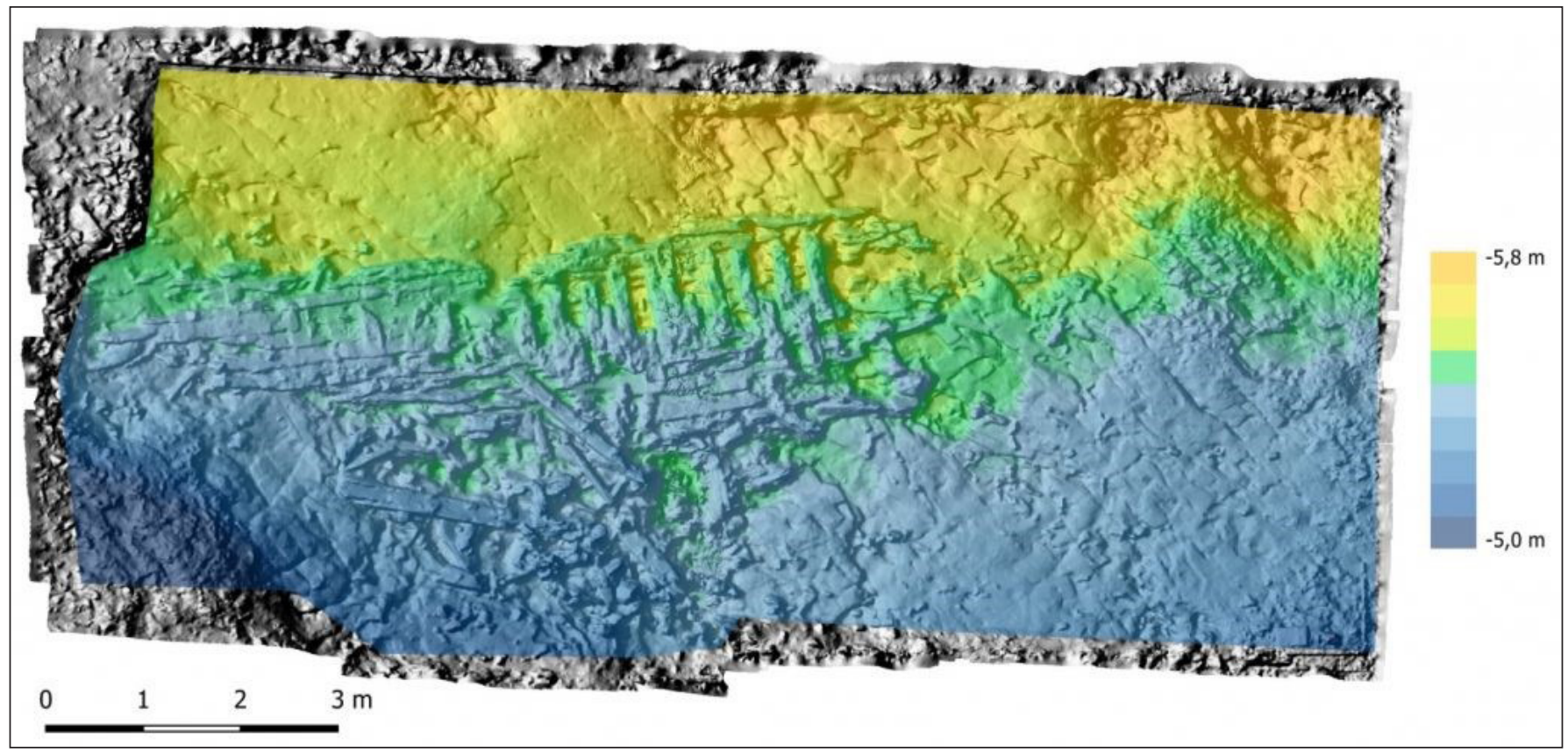

Fig. 9. 3D model of the wreck's structure (R. Scholz) 